\title{
Reflexiones sobre el teletrabajo en Colombia
}

\author{
Reflections on teleworking in Colombia \\ Lilian J. Fernández Rodríguez ${ }^{1}$
}

\begin{abstract}
RESUMEN
El presente trabajo tiene como objetivo general identificar la historia, las clases y características de esta nueva modalidad del trabajo. Se subdivide en estas tres partes, con el fin de identificar en donde nació el teletrabajo, cual ha sido su evolución histórica, definición legal y conceptual, así como sus características principales, ventajas y desventajas de la utilización de esta figura jurídica. El artículo cierra con unas conclusiones provisionales del tema.
\end{abstract}

\section{Palabras claves:}

Teletrabajo, Precedente judicial, Nuevo derecho.

\begin{abstract}
The purpose of this work is to identify the history, classes and characteristics of this new modality of work. It is subdivided into these three parts, in order to identify where telecommuting was born, which has been its historical evolution, legal and conceptual definition, as well as its main
\end{abstract}

\footnotetext{
${ }^{1}$ Abogada, Magister en Derechos y Negociones Internacionales de la Universidad Europea del Atlántico. Secretaria General de la Corporación Universitaria Uniciencia. Docente y Ex Decana de la misma Corporación. secretaria.general@uniciencia.edu.co.
}

Recibido: 25 de marzo de 2019. Aprobado: 16 de Mayo de 2019.

Revista Legem, Universidad del Atlántico 5 (1), Enero - Junio 2019, pp. 23-51

ISSN: 2346-2787 
characteristics, advantages and disadvantages of the use of this legal figure. The article closes with some provisional conclusions on the subject.

\section{Key words:}

Telecommuting, Judicial Precedent, New Right.

\section{Introducción}

El trabajo como parte fundamental de nuestra vida, ha ido evolucionando de acuerdo a los modos de producción de la humanidad: La Sociedad Primitiva, se caracterizó porque los hombres se organizaron a través de Clanes, Gens y/o tribus, eran hombres nómadas, que se desplazaban de un sitio para otro. Cada miembro de la tribu colaboraba para su subsistencia. No existían división de clases sociales y los bienes comunes eran de todos. Posteriormente surge la Sociedad Esclavista caracterizada porque el hombre se vuelve sedentario, aparece la propiedad privada, que lleva como consecuencia la división de clases sociales como amos y esclavos y comienza a desarrollarse las Polis o Ciudad Estado. La Sociedad Feudal distinguida por la desaparición de los esclavos, pero aparece una nueva clase social denominado siervo y su señor. El lugar de producción era principalmente el taller, el lugar central eran los feudos.

Por último, surge la Sociedad Capitalista, diferenciada porque aparecen los burgueses y los proletarios. Desaparece el taller y es la fábrica la que comienza a ser el lugar de producción. Existe un desplazamiento de las personas que prefieren vivir en las ciudades que en los campos. La clase proletaria se organiza y aparecen ideologías en las que se destaca el marxismo y anarquismo. 
A la par de estas sociedades, el estado implementa modelos económicos a saber:

1. El liberalismo: Este modelo se adopta a raíz de pensadores como Adam Smith en su libro riqueza de las naciones, en donde se propende por la realización de libertades individuales de tal manera que el estado interviniera lo menos posible. Su famoso Laissez Affaire "dejar hacer, dejar pasar", que conllevo a injusticias y a una desigualdad cada día más marcada entre las clases sociales.

2. El Desarrollismo: surge por la caída de la bolsa de Wall Street de 1929, la depresión de la economía. Es donde Keynes aparece desarrollando su modelo basado en un estado interventor que interviene directamente en los sectores productivos de la economía.

3. El Neoliberalismo: surge por la crisis del petróleo de la década de los 70 . Retoman los principios de Adam Smith, dejando que sea el sector privado el que intervenga de manera directa en la economía. El estado le entrega sus recursos para que estos sean los que la administren.

\section{Origen del Derecho al trabajo en Colombia}

En el siglo XX la discusión del derecho al trabajo, giraba en torno a la naturaleza jurídica del contrato laboral y la relación de trabajo. Frente a este desarrollo tardío el del profesor Romagnoli señala:

“(...) al derecho del trabajo se le reconoce muy tarde un status académico distinto al de un "intruso no autorizado". Nacido de una costilla del derecho privado, hasta mediados del siglo XX fue una disciplina accesoria también en la organización universitaria del saber jurí- dico, aunque ésta había dado paso a las especializaciones desde finales del siglo XIX" (ROMAGNOLI, 1997) 
En Colombia, existía poca normatividad frente a este aspecto, solo aparecía referenciado de manera vaga el trabajo por cuenta ajena, hasta que se expidió el Código Sustantivo de Trabajo en el año 1961, mediante la Ley 141. Este código se caracteriza por resaltar dentro de su normatividad el principio de la primacía sobre la realidad, convirtiéndolo en un derecho garantista, puesto que este consiste en que independientemente de la denominación que le den las partes al contrato, si concurre los tres elementos esenciales del trabajo (Arenas, 2007), esto es, prestación personal del servicio, subordinación y remuneración, debe considerarse como un contrato laboral.

Teniendo en cuenta, que Colombia, no ha sido ajena a la realidad social y a los cambios que se dieron en la economía, a través del Presidente Cesar Gaviria en el año 1990 con su lema "bienvenidos al futuro", dio paso a lo que se denominó en ese entonces la Apertura Económica, conllevando a una serie de reformas laborales que fueran de la mano con la nueva realidad económica del país. Es como surgen normas tales como la Ley 50 de 1990 y la Ley 100 de 1993, que regula todo lo relacionado con el derecho al trabajo y al Sistema de Seguridad Social Integral, conllevando a notables desmejoras para los trabajadores. No obstante, se debe resaltar que con la expedición de la Constitución Política de Colombia, en el año de 1991, elevo a derecho fundamental el derecho al trabajo y lo desarrollo en su artículo 53. Colombia forma parte de la Declaración Universal de los Derechos Humanos, el Pacto Internacional de Derechos Económicos, Sociales y Culturales, el Pacto Internacional de Derechos Civiles y Políticos, y la Convención Americana sobre Derechos Humanos.

El artículo 1 del Código Sustantivo del Trabajo (ley 789 de 2002), señala que su objetivo principal es lograr el equilibrio en las relaciones obrero-patronales, al encontrarse el trabajador desprotegido desde el punto de vista económico y social. Por ello se le otorga una serie de prerrogativas, como el principio de irrenunciabilidad, favorabilidad y la protección del trabajo. Por lo anterior, el derecho laboral colombiano tiene como regulador la Constitución Política de 1991, los tratados y convenios internacionales suscritos por Colombia y el Código Sustantivo del Trabajo. 
Características del derecho laboral colombiano:

1. El derecho laboral colombiano es reciente.

2. Es un derecho en formación que avanza a medida que surgen las necesidades.

3. Es un derecho que no tiene formalismos ya que es poco solemne porque surge de la realidad.

4. Tiene un claro sentido clasista por la desigualdad entre empleador y trabajador.

5. Tiende a la internacionalización por la incidencia de este derecho en la economía. Por esta razón se crea la OIT.

Principios del derecho laboral colombiano.

1) Finalidad: Se refiere a la justicia en la relación de empleadores y trabajadores, al equilibrio social y la coordinación económica.

2) Intervención del Estado: Esta intervención se da debido a que los intereses de las partes son contrarios, haciéndose necesaria la intervención de un tercero que en este caso es el Estado.

3) Derecho al trabajo y libertad de trabajo: Se fundamenta en el hecho de que el trabajo funciona como un derecho y una libertad (de escogencia y ejercicio) a la que tienen acceso todos los colombianos.

4) Obligatoriedad: El trabajo es también una obligación, porque es la única forma de lograr bienestar y desarrollo.

5) Igualdad de los empleados: Debe existir la igualdad entre hombres y mujeres, también entre el trabajo físico y el intelectual. La excepción se da respecto a la edad.

6) Derecho de asociación: Toda persona tiene derecho de pertenecer o no a una asociación. Generalmente la consecuencia de este derecho es la conformación de sindicatos.

7) Derecho a la huelga: Es un arma de presión eficaz de los sindicatos para alcanzar sus pretensiones. Se prohíbe a quienes presten servicios públicos esenciales. 
8) Derecho a la seguridad social: Esta subdivisión derecho laboral colombiano debe estar presente para ayudar al trabajador en sus épocas más vulnerables. Es una obligación del Estado y del empleador. El empleador debe asegurarse de que el empleado tenga un régimen para su protección.

9) Carácter de orden público de las normas laborales: Las normas laborales son de aplicación inmediata, obligatorias para cualquier habitante del país. Son derechos irrenunciables.

Ahora bien, el derecho laboral colombiano se caracteriza, por formar una teoría "clásica" en sus relaciones laborales. De acuerdo al artículo 22 del Código sustantivo del trabajo un contrato de trabajo: "es aquel en virtud del cual una persona natural o física, se compromete a prestar un servicio de manera personal, indelegable, a otra persona natural o jurídica, bajo una subordinación o dependencia, a cambio de una contraprestación o remuneración económica (PRESIDENCIA DE LA REPUBLICA, 1950)". Es así como determino el código laboral:

"para que haya contrato de trabajo se requiere que concurran estos tres elementos esenciales: a. La actividad personal del trabajador, es decir, realizada por sí mismo;

b. La continuada subordinación o dependencia del trabajador respecto del empleador, que faculta a éste para exigirle el cumplimiento de órdenes, en cualquier momento, en cuanto al modo, tiempo o cantidad de trabajo, e imponerle reglamentos, la cual debe mantenerse por todo el tiempo de duración del contrato. Todo ello sin que afecte el honor, la dignidad y los derechos mínimos del trabajador en concordancia con los tratados o convenios internacionales que sobre derechos humanos relativos a la materia obliguen al país; y

c. "Un salario como retribución del servicio".. 
Debido al carácter público y de obligatorio cumplimiento de este tipo de disposiciones, la norma agrega:

"2. Una vez reunidos los tres elementos de que trata este artículo, se entiende que existe contrato de trabajo y no deja de serlo por razón del nombre que se le dé ni de otras condiciones o modalidades que se le agreguen". (PRESIDENCIA DE LA REPUBLICA, 1950)

En cuanto al primer elemento, esto es, la prestación personal del servicio, exige que, para el cumplimiento de las obligaciones estipuladas en el contrato y las que se deriven de este, esas actividades sean realizadas exclusivamente por el empleado. Lo cual implica la imposibilidad de que el empleado delegue, bajo cualquier modalidad, a otra persona, para la realización de las mismas. El segundo elemento por su parte, requiere la existencia de una relación de subordinación o dependencia del trabajador respecto del empleador. Ello implica entonces, la emisión de órdenes bajo cualquier modalidad, las cuales deberán ser cumplidas a cabalidad por el empleado y el cumplimiento de una jornada laboral, el cual no podrá exceder de cuarenta y ocho (48) horas semanales, de acuerdo a nuestra legislación vigente.

Este segundo elemento, es el más importante, ya que determina si es o no contrato laboral. Si es claramente identificable la jerarquía nos encontramos frente a un vínculo contractual de naturaleza laboral. Según la Corte Constitucional colombiana, en Sentencia C-386 de 2000, la subordinación es entendida:

"como un poder jurídico permanente de que es titular el empleador para dirigir la actividad laboral del trabajador, a través de la expedición de órdenes e instrucciones y la imposición de reglamentos, en lo relativo a la manera como éste debe realizar las funciones y cumplir con las obligaciones que le son propias, con miras al cumplimiento de los objetivos de la empresa, los cuales son 
generalmente económicos. Se destaca dentro del elemento subordinación, no solamente el poder de dirección, que condiciona la actividad laboral del trabajador, sino el poder disciplinario que el empleador ejerce sobre éste para asegurar un comportamiento y una disciplina acordes con los propósitos de la organización empresarial y el respeto por la dignidad y los derechos de aquél". (CORTE CONSTITUCIONAL, 2000)

Sin embargo, los poderes o facultades que confiere el contrato de trabajo al empleador sobre el empleado no son absolutos. Poseen unos límites constitucionales, legales, consensuales y/o por vía del derecho internacional. Estos límites, según la Corte Constitucional en la Sentencia referida, son: "i) la Constitución; ii) los convenios y tratados internacionales sobre derechos humanos; iii) la ley, los contratos, los acuerdos y convenios de trabajo, los cuales "no pueden menoscabar la libertad, la dignidad humana ni los derechos de los trabajadores".

Esta posición ya había sido sostenida por la Corte en sus inicios, cuando en Sentencia C-299 de 1998, sostuvo que

“... la subordinación a la que está sujeto el trabajador en el contrato de trabajo rige solamente para los efectos propios que se derivan de la relación laboral, es decir, para el cumplimiento de la actividad, servicio, o labor contratada y que, como se expresó, permite al empleador dar órdenes, dirigir al trabajador, imponerle reglamentos, o sancionarlo disciplinariamente.." (CORTE CONSTITUCIONAL, 1998)

El tercer elemento, un salario como retribución del servicio, es decir, es la contraprestación que recibe el empleado por la prestación de un servicio. 
Una vez se configura estos tres elementos, de acuerdo a la legislación los contratos de trabajo según su forma, se clasifican en verbales o escritos, y su validez no se desprende de una formalidad especial, pero siempre el contrato a término fijo deberá ir por escrito de lo contrario no tendrá validez alguna. Es decir, el contrato verbal es aquel cuyo acuerdo y estipulaciones no constan por escrito. En esta clase de contrato, deberá señalarse:

- Clase de trabajo

- Sitio donde se prestara el servicio

- Duración del contrato

- Forma de remuneración

La omisión de alguno de estos requisitos podrá ser suplida por la realidad, pero cuando se trate de la remuneración, el artículo 144 del CST señala:

"que al trabajador se le pagara un salario equivalente al que se paga a otras personas por desempeñar la misma labor, y en caso tal de no haber una referencia, la tasación se hará teniendo en cuenta la aptitud del trabajador la cantidad y calidad del trabajo". (PRESIDENCIA DE LA REPUBLICA, 1950)

Cuando el contrato se haga de manera escrita, el artículo 39 del CST señala que debe extenderse una copia para el trabajador y otra para el empleador. En el contrato deben identificarse plenamente las partes y sus respectivos domicilios, el lugar y fecha de celebración del contrato, el lugar donde se prestara el servicio, la naturaleza del trabajo, la remuneración, periodo y formas de pago, y las circunstancias particulares que el trabajador y el empleador quieran contemplar. También debe dejarse claro si se pactan jornales o sueldo, ya que el primero implica que el pago se hará cada semana, y el segundo contempla como periodo máximo de pago, el mes vencido. 
De acuerdo a su duración tenemos:

- Contrato a término fijo

Es exigencia legal que esta clase de contrato conste SIEMPRE por escrito, su duración máxima inicial es de tres años (por el tema de la prescripción), pero podrá ser renovado indefinidamente.

La consecuencia de no realizarse por escrito, es que el contrato se entenderá celebrado por término indefinido.

Podría hablarse de una sub - clasificación en este tipo de contrato así:

\section{Contrato a término fijo inferior a un año}

Se caracteriza por: constar siempre por escrito; necesidad de dar preaviso escrito no inferior a 30 días de no prorrogar el contrato salvo que se trate de un contrato a término fijo hasta de 30 días; puede prorrogarse inicialmente hasta por tres períodos iguales o inferiores al término inicial pero este último debe constar siempre por escrito, de haber silencio, se entenderá prorrogado por un término igual al inicial; después de la tercer prorroga la renovación mínima deberá ser de un año, si hay silencio se entenderá ser renovado por un año; las prórrogas no podrán ser superiores al término inicial.

Los trabajadores a término fijo tienen derecho a todas las prestaciones que se causen de acuerdo con la ley, y a las vacaciones y prima de servicios cualquiera sea el tiempo servido. El periodo de prueba será una quinta parte del periodo inicial, sin exceder los dos meses.

2. Contrato a término fijo de uno a tres años 
Se caracteriza por: posee los mismos rasgos diferenciadores que el anterior, solo que se diferente porque no existe límite de renovaciones, y sin convertirse en un contrato a término indefinido

- Contrato de trabajo a término indefinido

Esta es la regla general en materia de contratación laboral, ya que cuando no se estipula otro tipo de contrato, se entenderá que se está en presencia de un contrato a término indefinido.

Este contrato está vigente mientras no cambien las causas que le dieron origen, en caso de darse una terminación con justa causa por parte del empleador, este no estará obligado a indemnizar al trabajador, de no haber justa causa, deberá además de indemnizar, reintegrar al trabajador a sus labores

- Contrato de trabajo Accidental, Ocasional, Transitorio

El artículo 6 del CST define este tipo de contrato como aquel que se caracteriza por ser de corta duración, no mayor de un mes y para realizar labores distintas al giro ordinario de los negocios del empleador.

Requisitos:

- La duración no puede ser mayor a un mes

- La actividad debe ser diferente a la que desempeña el empleador habitualmente. 
Los trabajadores accidentales, ocasionales, o transitorios, tiene derecho a cesantía y a prima de servicios proporcional al tiempo laborado, no tendrán derecho a calzado, vestido de labor, por cuanto su labor solo dura un mes.

También tendrán derecho a que se paguen proporcionalmente las vacaciones, a ser afiliados al sistema de seguridad social (salud, pensión, riesgos laborales).

- Contrato por duración de la obra o labor determinada

Este contrato se celebra por el tiempo en el que se desarrolle la obra o labor que se contrata. No se ha establecido ni un mínimo ni un máximo para este contrato, tenemos como ejemplo la construcción de un edificio, la recolección de una encuesta, reemplazo de un trabajador incapacitado, entre otros. A diferencia del contrato a término fijo, este tipo de contrato no requiere un preaviso escrito de que se va terminar el contrato, ya que finalizada la obra se entiende haberse dado por terminado el contrato. Los trabajadores bajo esta modalidad, tienen derecho a todas las prestaciones sociales que se causen durante la obra. También tienen derecho a las vacaciones, ya sea disfrutadas, si la obra dura más de un año, o compensadas si dura menos. Deberán ser afiliados estos trabajadores al sistema de seguridad social (salud, pensión, riesgos laborales).

- Contrato de aprendizaje

Se entiende como una forma especial por medio de la cual una persona no subordinada en un plazo no mayor a dos años, recibe formación teórica en una entidad de formación autorizada, con el patrocinio de una empresa que suministra los medios para adquirir la formación práctica, propia del giro ordinario de los negocios de la empresa patrocinadora que reconocerá un apoyo para sostenimiento mensual, que en ningún caso constituirá salario. 
Los anteriores elementos y formas de contratación señalados, se redefinen y se flexibilizan, la que conlleva al surgimiento de nuestro tema de estudio, el teletrabajo, tiene una explicación de tipo sociológico, la cual estudiaremos -en el capítulo tres desde la óptica de autores como Michael Foucault, Gilles Deleuze y Mauricio Lazzarato, para, posteriormente, enfocarnos en las tendencias constitucionales de la Corte frente al teletrabajo en Colombia.

\section{Antecedentes históricos del Teletrabajo}

Hacia 1973, en plena crisis petrolera surge el teletrabajo a través del norteamericano Jack Nilles, en ese entonces, una de las principales preocupaciones era el abastecimiento de combustible, por lo que surge la idea de llevar el trabajo a donde se encontraba el trabajador, concepto que se torna atractivo, teniendo en cuenta la escasez que se estaba viviendo. Por lo anterior, surgen nombre en inglés tales como "telecommutting" (en inglés "to commute" implica viajar todos los días entre el hogar y el trabajo).

En esa época, existían computadoras e internet, pero su uso en Estados Unidos, se hizo generalizado solo dos décadas después. En un inicio, el teletrabajo solo era usado para aquellos altos ejecutivos, que tenían el privilegio de trabajar desde sus hogares.

Posteriormente, IBM decide probar esta modalidad para sus trabajadores, de manera que las personas comenzaron a trabajar desde sus hogares, logrando por un lado reducir costos y por el otro aprovechar el tiempo libre.

En Alemania y Austria, comienzan a implementar los llamados "telecentros", con el objeto de desarrollar aquellas zonas rurales. 
Esta es la razón, por la que existen marcadas diferencias entre la concepción del teletrabajo en Estados Unidos y en Europa, para los primeros, cualquier persona que esté trabajando fuera del lugar del trabajo está ejerciendo una labor de teletrabajo; para los segundos, el elemento clave es el uso de las tecnologías de la información. Lo que sí es común para los dos, son los beneficios que conlleva la implementación de esta nueva modalidad de trabajo. De ahí, que las empresas se preocupan por mejorar la infraestructura técnica de telecomunicaciones, con el fin de reducir costos y mejorar la productividad, conllevando el mejoramiento de la calidad de vida de las personas, por la mejor utilización de su tiempo.

En Latinoamérica, el teletrabajo como una nueva modalidad de empleo, lleva muy poco tiempo de utilización. Chile fue el primer país en brindar un marco legal para el teletrabajo, modificando sus normas laborales con el fin de que los teletrabajadores quedaran excluidos de la limitación de la jornada laboral.

\section{Historia del Teletrabajo en Colombia}

En Colombia, los primeros antecedentes del teletrabajo se encuentran en el trabajo a domicilio, el cual tradicionalmente se ha considerado como una forma de trabajo dependiente puesto que "el trabajador a domicilio no trabaja para sí, como el artesano o el pequeño industrial, sino para otros cumpliendo las directivas e instrucciones del dador del trabajo" (Gereis K, 2005), modalidad consagrada en el artículo 89 del CST en donde establece "Hay contrato de trabajo con la persona que presta habitualmente servicios remunerados en su propio domicilio, sola o con la ayuda de miembros de su familia por cuenta de un empleador". (PRESIDENCIA DE LA REPUBLICA, 1950)". Pero su consagración expresa surge con la Ley 1221 de 2008 "Por la cual se establecen normas para promover y regular el Teletrabajo y se dictan otras disposiciones"; el Decreto 884 de 2012 "Por medio del cual se reglamenta la Ley 1221 de 2008 y se dictan otras disposiciones" y la Resolución 2886 de 2012 "Por la cual se definen las entidades 
que harán parte de la Red Nacional de Fomento al Teletrabajo y se dictan otras disposiciones".

Las entidades que se han encargado de reglamentar y divulgar esta modalidad de trabajo son el Ministerio de la Tecnología y las Telecomunicaciones TIC's, y el Ministerio del Trabajo.

\section{Etimología}

El vocablo teletrabajo "proviene de tele y trabajo, cuyo significación etimológica nos conduce a expresarlo, habida cuenta que la raíz latina tele denota distancia o lejanía, como un trabajo ejecutado a distancia" (ARMAS MORALES, 2005)

De acuerdo al Diccionario de la Real Academia Española, define al teletrabajo como "Todo trabajo que se realiza desde un lugar fuera de la empresa utilizando las redes de telecomunicación para cumplir con las cargas laborales asignadas" (REAL ACADEMIA DE LA LENGUA ESPAÑOLA, s.f.)

\section{Definición legal}

El teletrabajo se entiende como una modalidad laboral que usa las tecnologías de la información y las comunicaciones (TIC's).

El teletrabajo se encuentra definido en la Ley 1221 de 2008 como:

"Una forma de organización laboral, que consiste en el desempeño de actividades remuneradas o prestación de servicios a terceros utilizando como 
soporte las tecnologías de la información y comunicación -TIC- para el contacto entre el trabajador y la empresa, sin requerirse la presencia física del trabajador en un sitio especifico de trabajo" (CONGRESO DE LA REPUBLICA, 2008)

\section{Definición Doctrinal}

Orihuel Pérez de los Cobos, define el teletrabajo como:

"la realización de trabajo a distancia (principalmente en tareas administrativas, aplicaciones de software y ciertas actividades comerciales) utilizando técnicas de la telecomunicación y/o de la informática. Además, es una forma de exteriorizar el trabajo del centro empresarial hacia los lugares en donde se desempeñaran los empleados. Las nuevas tecnologías son el medio o instrumento que hace posible la exteriorización de ciertas actividades que por su naturaleza debían prestarse en las instalaciones de la empresa (PÉREZ, 1990)".

Xavier Thinault, lo define como "una forma de organización y/o ejecución del trabajo realizado a distancia, en gran parte o principalmente, mediante el uso intensivo e las técnicas informáticas y/o de telecomunicaciones." (THIBAULT, 1998)

\section{Modalidades de Teletrabajo}

La Ley 1221 de 2008 regula el ejercicio del teletrabajo a través de las siguientes modalidades: 
> Teletrabajo autónomo: ejecutan las labores desde cualquier lugar elegido por ellos, se valen de las TIC's para el desarrollo de sus tareas.

> Teletrabajo suplementario: Unos días trabaja en la empresa y otros días fuera de ella, usando las TIC para dar cumplimiento.

Deletrabajo móvil: utilizan dispositivos móviles para ejecutar sus tareas, no tienen un lugar de trabajo establecido.

Según la investigadora de la Universidad Externado Marcela Rodríguez el teletrabajo además, presenta diversas modalidades por medio de las cuales puede ser ejecutado. Entre estas encontramos las siguientes:

A. Oficina Satélite: "Son aquellas oficinas que hacen parte de la empresa y que se encuentran ubicadas en lugares estratégicos cercanos al domicilio de un grupo de trabajadores. En esta modalidad no importan las funciones que realizan los trabajadores al interior de la empresa. $Y$ es precisamente esto último una de las razones por las cuales no consideramos que en esas oficinas satélites se desarrolle el teletrabajo porque como no interesa la función que realice el trabajador, así mismo no es una herramienta fundamental del trabajo los sistemas de información como lo es Internet, que sabemos es un elemento esencial".

B. Los Telecentros: "Son oficinas satélites donde se reúnen trabajadores de varias empresas. Cabe aquí la misma crítica planteada para las oficinas satélites agregando que en este caso no se logra el equilibrio buscado por el teletrabajo entre los beneficios obtenidos por el trabajador y los obtenidos por el empleador. 
A pesar que el tema de los beneficios no se ha planteado aún en este escrito, toda vez que sobre él se hablará posteriormente, se hace evidente que con los Telecentros los máximos beneficiados serán las empresas en la medida que reducirán sus costos de funcionamiento al compartir los mismos entre ellas, mientras que el beneficio supuestamente obtenido por los trabajadores con esta modalidad de trabajo: la cercanía de sus hogares al Telecentro difícilmente se hará realidad siempre que resulte prácticamente imposible lograr la cercanía de éste a los hogares de todos ellos".

C. Telecottages: "Son locales con herramientas de información como computadores, escáner, impresora, fax, conexión a Internet y telefonía móvil ubicados en pequeños pueblos; creados por Fundaciones con la colaboración del Estado, que busca acercar el empleo a sus habitantes, facilitándole los medios para lograr vincularse laboralmente con una empresa bajo la modalidad de teletrabajo. Esta modalidad tiene gran desarrollo en Canadá, en los Países Nórdicos, en Irlanda y en Inglaterra".

D. Móviles o Nómadas: Supone que el trabajador no tiene un lugar determinado para ejecutar su trabajo, ya que por las mismas características de éste se le hace necesario movilizarse constantemente pero siempre contando con el Internet como herramienta básica para el desenvolvimiento de sus funciones, y como sabemos, esto es posible si se tiene un computador portátil con conexión inalámbrica a Internet; el ejemplo típico es el trabajador que desarrolla labores de ventas" (RODRÍGUEZ, 2017).

\section{Características de Teletrabajo}

$>$ Utilización de tecnologías para facilitar la comunicación para cumplir sus funciones.

> Actividad laboral que se lleva a cabo fuera de la organización. 
Modelo organizacional que replantea las formas de comunicación interna de la organización.

$>$ Horarios flexibles.

$>$ Trabajo desde cualquier lugar.

$>$ Dispositivos propios (BYOD).

$>$ Evaluación por resultados.

$>$ Reuniones virtuales con participantes ilimitados (Min TIC 2012).

\section{Sistema de contratación mediante teletrabajo en Colombia}

Para que exista la modalidad de teletrabajo, el mismo debe constar por escrito, en donde se estipule claramente el lugar donde se va a realizar la actividad laboral. Igualmente, se deben definir las metas que el teletrabajador debe cumplir. La forma como se deben rendir los informes, de qué manera se van a realizar las reuniones y los canales oficiales de comunicación. Adicional, se debe tener en cuenta que se le deberá cancelar al trabajador un valor por gastos relacionados con la tarifa de energía. Dependiendo de la modalidad de contratación adoptada deberá estipular los días en que trabajará tanto en la empresa como en la casa.

Dentro de las garantías de los teletrabajadores podemos encontrar unas de tipo legal, encaminadas a proteger las garantías laborales, sindicales y de seguridad social, y otras de rango constitucional, las cuales tienen su fundamento en el derecho a la igualdad.

Dentro de las primeras podemos citar las siguientes:

“1. A los teletrabajadores, dada la naturaleza especial de sus labores no les serán aplicables las disposiciones sobre jornada de trabajo, horas extraordinarias y trabajo nocturno. No obstante la anterior, el Ministerio de la Protección Social deberá adelantar una vigilancia especial para garantizar que los teletrabajadores no sean sometidos a excesivas cargas de trabajo. 
2. El salario del teletrabajador no podrá ser inferior al que se pague por la misma labor, en la misma localidad y por igual rendimiento, al trabajador que preste sus servicios en el local del empleador.

3. En los casos en los que el empleador utilice solamente teletrabajadores, para fijar el importe del salario deberá tomarse en consideración la naturaleza del trabajo y la remuneración que se paga para labores similares en la localidad.

4. Una persona que tenga la condición de asalariado no se considerará teletrabajador por el mero hecho de realizar ocasionalmente su trabajo como asalariado en su domicilio o en lugar distinto de los locales de trabajo del empleador, en vez de realizarlo en su lugar de trabajo habitual.

5. La asignación de tareas para los teletrabajadores deberá hacerse de manera que se garantice su derecho a contar con un descanso de carácter creativo, recreativo y cultural.

6. Lo dispuesto en este artículo será aplicado de manera que se promueva la igualdad de trato entre los teletrabajadores y los demás trabajadores, teniendo en cuenta las características particulares del teletrabajo y, cuando proceda, las condiciones aplicables a un tipo de trabajo idéntico o similar efectuado en una empresa”. (CONGRESO DE LA REPUBLICA, 2008)

Dentro de las garantías constitucionales, que buscan la protección del derecho a la igualdad, podemos citar los siguientes ámbitos:

“a) El derecho de los teletrabajadores a constituir o a afiliarse a las organizaciones que escojan y a participar en sus actividades;

b) A protección de la discriminación en el empleo; 
c) La protección en materia de seguridad social (Sistema General de Pensiones, Sistema General de Seguridad Social en Salud y riesgos profesionales), de conformidad con lo previsto en la Ley 100 de 1993 y las normas que la modifiquen $\mathrm{o}$ adicionen $\mathrm{o}$ en las disposiciones que regulen los regímenes especiales;

d) La remuneración;

e) La protección por regímenes legales de seguridad social;

f) El acceso a la formación;

g) La edad mínima de admisión al empleo o al trabajo;

h) La protección de la maternidad. Las teletrabajadoras tendrán derecho a retornar al mismo puesto de trabajo o a un puesto equivalente con la misma remuneración, al término de la licencia de maternidad.

i) Respeto al derecho a la intimidad y privacidad del teletrabajador"

En cuanto a las obligaciones de las partes, es necesario resaltar los teletrabajadores estarán afiliados al sistema de seguridad social, y el pago de los aportes de estos deberán efectuarse a través de la planilla integrada de liquidación de aportes (PILA). En lo que respecta a los gastos propios del ejercicio de la labor del trabajador, tales como equipos de trabajo, conexiones, programas, energía (tales como las de los servicios públicos; ya que los gatos del funcionamiento de la empresa no pueden ser trasladados al trabajador), y desplazamientos, estos están a cargo del empleador, según el artículo 6 de la Ley 1221 de 2008. 
De otro lado, la jornada laboral de los teletrabajadores no aparece, en la normatividad legal que hemos revisado, de manera expresa, sí nos dice la norma que en el contrato debe aparecer los días y horarios en que se realizarán las actividades (ello para efectos de delimitar las responsabilidad en caso de accidente); en ese sentido, la jornada del teletrabajador no podrá en ningún caso exceder la jornada laboral máxima establecida por la ley. Dentro de las obligaciones específicas del empleador podemos citar las siguientes: Diligenciar el formulario de aporte de novedades, en el cual se debe indicar de manera expresa que el trabajador estará vinculado bajo la modalidad de teletrabajo. Allegar copia del contrato a las entidades de riesgos laborales y de seguridad social. En caso de ser persona de derecho público, allegar el respectivo acto administrativo. Verificar las condiciones de trabajo, para lo cual supervisará, a través del autoreporte, las condiciones de seguridad y salud del teletrabajador. Incorporar dentro de su respecto reglamente interno las condiciones especiales bajo las cuales operará el teletrabajo.

En el caso del sector público, las entidades deberán adoptar manuales de función y competencias laborales. Realizar los respectivos pagos correspondientes a seguridad social y ARP. Informar a los teletrabajadores sobre las políticas de la empresa o entidad sobre los programas de salud. Por su parte, el trabajador está obligado a: Diligenciar el formato de autoreporte. Cumplir con todas las normas en torno al sistema de seguridad social y de riesgos laborales. Cumplir a cabalidad cada una de las obligaciones y /o clausulas estipuladas en el contrato. Utilizar en formas adecuada los equipos suministrados por el empleador para el ejercicio de sus funciones. Hacer uso razonable de recursos tales como la energía eléctrica.

Para el cumplimiento de esta normatividad y de las garantías de los teletrabajadores se creó, en el año de 2008, la Red Nacional del Fomento al Teletrabajo, entidad que, coordinada por el Ministerio del trabajo,

"1. Convocará la integración de mesas de trabajo, que se conformarán por aspectos tecnológicos, formativos, organizativos, legales, y una mesa especial sobre población vulnerable; estas mesas deberán generar una agenda anual 
para el desarrollo de las actividades. 2. Trabajará en la generación y desarrollo de las políticas públicas definidas en la Ley 1221 de 2008 en cuanto al fomento del teletrabajo, generación de incentivos y en la política especial de teletrabajo en la población vulnerable. 3. Fomentará la posibilidad que las empresas adopten el contrato de teletrabajo, para las mujeres antes de entrar a licencia de maternidad y durante la etapa de lactancia, con el ánimo de flexibilizar el sistema y fomentar la equidad de género en el ámbito laboral" (PRESIDENCIA DE LA REPUBLICA, 2012).

De igual manera, no solamente el Ministerio del Trabajo sino también el Ministerio de Tecnologías de la Información y las Comunicaciones tendrá un conjunto de obligaciones que deberá realizar con miras a promocionar y supervisar la correcta implementación y ejecución el teletrabajo. Estas funciones pueden resumirse de la siguiente manera:

“1. Promover el uso, apropiación y masificación de las tecnologías de la información y las comunicaciones mediante la promoción, difusión y fomento del teletrabajo.

2. Promover e impulsar la cultura del teletrabajo en el país, a través de planes y programas de promoción y difusión del teletrabajo incrementando el uso y apropiación de las tecnologías de la información y las comunicaciones.

3. Promover la inclusión laboral de población con discapacidad mediante el teletrabajo, a través del acceso a las tecnologías de la información y las comunicaciones para el contacto entre el trabajador y la empresa.

4. Apoyar al Ministerio del Trabajo en la formulación de planes y programas que incentiven la implementación de prácticas de teletrabajo. (PRESIDENCIA DE LA REPUBLICA, 2012). 


\title{
1.7 Ventajas y desventajas del teletrabajo
}

\author{
1.7.1 Ventajas del Teletrabajo
}

> Ahorro de tiempo y de dinero, teniendo en cuenta que los teletrabajadores cumplirán con sus actividades laborales dentro de la casa, sin pérdida de tiempo, ya que no habrán desplazamientos.

Fomenta la unión familiar y el contacto directo y más constante entre los padres e hijos. Con lo cual podría decirse que se fortalece el concepto de familia, al menos en el sentido de que permite al trabajador, tanto padre como madre -con independencia del sexo- la presencia en su hogar todos los días. Los espacios familiares no se verían truncados por las obligaciones laborales.

> Generación de empleos para aquellos grupos poblacionales que, por sus condiciones desventajosas, son generalmente excluidos de oportunidades laborales, tales como personas con discapacidades para movilizarse o desarrollar de manera articulada cada uno de sus sentidos.

> Permite la generación de empleos para personas pertenecientes a países diferentes a donde reside la empresa, con lo cual los extranjeros no tendrían que realizar trámites costosos y dispendiosos.

Mejoramiento de la calidad de vida de los teletrabajadores, por la optimización del tiempo libre y actividades personales. 
> Para las empresas, conlleva un ahorro de dinero y de espacio, puesto que no deben disponer de una oficina, ni de otros servicios que deberá prestar a los trabajadores cuando trabajan en el lugar de domicilio del empleador tales como servicios públicos, cafetería, entre otros.

$>$ Se aumentará la productividad del trabajador, siempre que las metas queden claramente establecidas.

$>$ De igual forma el teletrabajo produce beneficios de tipo ambientales, ya que al reducirse el número de personas que deben utilizar transporte para llegar a sus lugares de trabajo, necesariamente se presentará una reducción en el número de vehículos utilizados, o al menos, y con ello se contribuiría con los procesos de movilidad urbana -especialmente en las grandes ciudades-, se reducirá la congestión vehicular y los niveles de contaminación (especialmente la contaminación del aire producidos por el dióxido de carbono de la combustión de los derivados del petróleo).

> Política "Bring Your Own Device -BYOD-" que aprovecha los dispositivos de propiedad del trabajador y no aumenta costos para la organización.

\section{Desventajas del Teletrabajo}

Autodisciplina y autoorganización que debe tener el trabajador, ya que sin ello difícilmente podrá cumplir adecuadamente sus funciones.

> Sentimiento de soledad, teniendo en cuenta que la interacción del teletrabajador con otras personas bajara considerablemente. 
Pérdida de identidad corporativa, ya que por la distancia se le dificultara al empleador motivar a los teletrabajadores para el cumplimiento de sus objetivos.

> Dificultad de supervisión por parte del empleador, de las actividades ejecutadas por parte del teletrabajador.

\section{Conclusiones}

Como se pudo apreciar en este capítulo, las formas de trabajo se adaptan de acuerdo al modelo económico adoptado. En el caso de Colombia, pasamos de un estado de bienestar garantista a un estado neoliberal, que les entrega a los particulares los recursos para que sean ellos los que los administren. Esto produjo, una profunda trasformación económica y social que conlleva a generar nuevas modalidades de trabajo. Es allí donde surge el teletrabajo, como una modalidad acorde a las nuevas perspectivas del mundo, ya que incorpora las tecnologías y los sistemas de información, de tal manera que el trabajador, desde cualquier lugar del mundo, puede desempeñar las labores para los cuales ha sido contratado.

Es importante resaltar, que con esta nueva modalidad de trabajo y acorde a lo que se señaló surge una variación a la teoría clásica de la subordinación, ya que se deberá implementar nuevos controles acordes al avance tecnológico, con el fin de medir la productividad del trabajador. De otra parte, se tiene que el teletrabajador goza de todas las prerrogativas consagradas en el Código Sustantivo de Trabajo, de tal manera que se le garantice unos mínimos que el empleador debe respetar, en razón al principio de igualdad que debe regir todas las relaciones laborales. 
Colombia, ha hecho esfuerzos grandes por incorporar dentro de su legislación esta nueva modalidad de trabajo y su divulgación está a cargo de los dos Ministerios, con el fin de que sea incluida y adoptada en todas las empresas. Por último, podemos señalar que el teletrabajo es una nueva modalidad de trabajo, que presenta características únicas y muchísimas ventajas para las empresas y para los trabajadores, el utilizar esta figura, teniendo en cuenta el auge creciente de las telecomunicaciones y de los sistemas de información.

\section{Referencias.}

Arenas Monsalve, G. (2007). La Estructura Normativa Del Sistema Colombiano De Seguridad Social. Bogota: Legis.

Armas Morales, C. (2005). El Teletrabajo. Revistas De Investigación De La Universidad Nacional Mayor De San Marcos, 7-11.

Asamblea General De Las Naciones Unidas. (1948). Declaración Universal De Derechos Humanos. Obtenido De Naciones Unidas: Http:/Www.Un.Org/Es/Universal-DeclarationHuman-Rights/

Asamblea Nacional Constituyente. (1991). Constitucion Politica De Colombia. Bogota: Gaceta Del Congreso.

Comisión De Derechos Humanos De Las Naciones Unidas . (1966). Naciones Unidas Derechos Humanos Oficina Del Alto Comisionado. Obtenido De Http://Www.Ohchr.Org/Sp/Professionalinterest/Pages/Ccpr.Aspx

Corte Constitucional. (1996). Senencia T-466. Bogota: Gaceta Del Congreso.

Corte Constitucional. (1998). Sentencia C-299. Bogotá: Gaceta Del Congreso.

Corte Constitucional. (1998). Sentencia T- 075. Bogota: Gaceta Del Congreso. 
Lazzarato Maurizio, N. A. (2001). Trabajo Inmaterial Formas De Vida Y Producción De Subjetividad. Río De Janeiro: Dp\&A Editora.

Ministerio Del Trabajo. (2016). Acuerdo Ministerial No Mdt. Ecuador: Registro Oficial.

Ministerio Del Trabajo Y Previsión Social. (1981). Ley 18018. Santiago De Chile: Diario Oficial.

Mintic. Libro Blanco. (2014). El Abc Del Teletrabajo En Colombia. Versión 3.0. Bogota: Ministerio De Tecnologia De La Información Y Las Comunicaciones.

Organizacion De Las Naciones Unidas. (13 De Diciembre De 2006). Convencion Internacional Sobre Los Derechos De Las Personas Con Discapacidad. Obtenido De Naciones Unidas Enable: Http://Www.Un.Org/Spanish/Disabilities/Default.Asp?ld=618

Organizacion Internacional Del Trabajo. (24-26 De 10 De 2016). International Labour Organitation. Obtenido De Http:/Www.Ilo.Org/Wcmsp5/Groups/Public/---Ed_Dialogue/--Sector/Documents/Publication/Wcms_531116.Pdf

Pérez, O. (1990). Nuevas Tecnologías Y Relación De Trabajo . Valencia.

Presidencia De La Republica. (1950). Decreto Ley 2663. Bogota: Gaceta Del Congreso.

Presidencia De La Republica. (1950). Decreto Ley 3743 Codigo Sustantivo Del Trabajo. Bogotá: Gaceta Del Congreo.

Presidencia De La Republica. (2012). Decreto 884. Bogota: Gaceta Del Congreso.

Presidencia De La Republica. (30 De Abril De 2012). Http://Www.Alcaldiabogota.Gov.Co. Obtenido De Decreto 884 De 2012: Http://Www.Alcaldiabogota.Gov.Co/Sisjur/Normas/Norma1.Jsp?l=47216

Real Academia De La Lengua Española. (S.F.). Diccionario De La Rae. Obtenido De Diccionario De La Rae: Http://Dle.Rae.Es/Srv/Search?M=30\&W=Teletrabajo

Rodríguez, M. (04 De 2017). Red De Revistas Científicas De América Latina Y El Caribe, España Y Portugal. Obtenido De El Teletrabajo En El Mundo Y Colombia.: Http:/Www.Redalyc.Org/Pdf/336/33613102.Pdf. 
Romagnoli, U. (1997). El Derecho, El Trabajo Y La Historia. España: Consejo Economico Y Social (España).

Superintendencia De Riesgos Del Trabajo. (2012). Resolución 1552. Argentina: Dirección Nacional Del Registro Oficial.

Thibault Aranda, X. (1998). Aspectos Jurídicos Del Teletrabajo. Revista Ministerio De Trabajo $Y$ Asuntos Sociales. 